\title{
A critical view to current economic topics through an Online- Forum activity
}

\section{Caballer Tarazona, Vicent ${ }^{a}$; and Caballer Tarazona, María ${ }^{b}$}

${ }^{\mathrm{a} D}$ Department of Economics and Social Sciences, Universitat Politècnica de València, Spain

${ }^{\mathrm{b}}$ Department of Applied Economics, Universitat de València, Spain

\begin{abstract}
In order to address the critical thinking and the knowledge of contemporary problems an online forum activity is proposed in this paper. The activity was applied within the World Economy subject in the degree of Business Administration. The main aim of this teaching proposal is to discuss some current issues and events in the international economic context which likely are not addressed in the syllabus. Through an online forum both teacher and pupils posted comments about some relevant topics related with the subject content. Students have the opportunity to expres their own opinion and provide additional information and resources such as news links, documentaries, Youtube videos and other kind of audio-visual material. Despite of this activity was non mandatory, the response was positive, high proportion of pupils (67.1\%) were involved in it and 877 comments were published. Thus, the result was satisfactory but there was also some aspects to improve. In addition, this activity is suitable for other subjects or even other university degrees as well and can be easily adapted and modificated.
\end{abstract}

Keywords: Innovative material; Teaching and learning experiences; Education economics, e-learning 


\section{Introduction}

World economy, like many other social, technical and medical sciences, is rapidly changing. Even more in the next years. Logically, subject syllabus can not contemplate the important alterations produced in the world along the academic year but students should know them. For instance, in the field of International Economics, some important events have occurred in recent times such as Bitcoin irruption, protectionist policies in United States or the advancement of renewable energies is some countries. The economic conditions may vary one year to the next. These kind of topics is not usually addressed along the course because the subject content is planned in advanced but it is convenient that the students discuss about that to develop critical thinking and the knowledge of contemporary problems. Moreover, it is possible that professor wants to show some additional content related with the subject but due to the lack of time can not be displayed. To achieve these and other aims a internet forum activity is proposed in this paper.

As it is possible to find in the literature about high education, online forums have been used for a long time for different purposes in higher education [1] especially in e-learning and blende education [2].

These kind of activities have a double goal. By one hand, regarding contents of the subject, student's implicit task is to be up to date with the subject, review what has been discussed in class, get competences progressively, detect possible concepts that have been misunderstood to realize about their weaknesses.

On the other hand, and regarding to the skill adquisition, these kind of activities are useful to promote self-learning among students and encouragion them to discover and make links between realty and theoretical contents teached in class.

In this line, according to Lee et al. [3], research-based methodologies allow students to develop skills such as self-reflection, critical thinking and responsibility for their own learning, thus producing intellectual growth and maturity.

Under this context, the aim of this paper is to presents an online forum activity in the World Economy subject which is taught in the second course of the Businees Administration Degree at the Universitat Politècnica de València (UPV). Its content is related mainly to trade policy, comparative advantage and international context of economy.

\section{Material and methods}

UPV provides an online platform for managing all subjects taught in this university called Polifomat [4]. This tool allows professor to oupload teaching material for students, publish marks, sent emails, post announces and other features. Among these, it is the online forum, 
which is not always used by professors and other times, its purpose is to solve doubts about the content or the course development. And the teacher either the students can propose doubts or debate topics and participate in the discussion.

\subsection{Subject context}

Table 1 shows information about the subject in which the activity was apply.

Table 1: Subject information.

\begin{tabular}{|l|l|}
\hline Subject & World Economy \\
\hline ECTS Credits & 4.5 \\
\hline Course & Second \\
\hline Degree & Business Administration \\
\hline Number of students & 76 \\
\hline Language & Spanish \\
\hline Modality & Presence-based \\
\hline
\end{tabular}

\subsection{Teaching activity}

The online forum was enabled through Poliformat. The teacher posted documentaries, news, videos or any other audiovisual material related with subject content. Due to the characteristics of the subject, this complementary material covers a wide range of topics. For instance, some teacher publications on the forum were the documentary Inside job [5], and videos or news about the Comprehensive Economic and Trade Agreement (CETA), North America Free Trade Agreement (NAFTA), current state of the world economy and globalization, the evolution of exports and imports in Spain, climate change, energy or world development, poverty and inequality. After reading or watching the content of the post, the students could express their opinion of the topic address and contribute with futher information. These participations should be reasoned and well-argued and not be copied from internet sites. Pupils had also the possibility to open new topics provided that these are linked with the syllabus. In addition, all comments had to be respectful and tolerant with both partners and any collective of persons. They could be expelled from the activity in case of not following these rules. All instructions were published in a forum rules post at 
the beginning of the activity. The forum stayed available along most part of the course, from one week after the beginning to three weeks to the end, what means 13 weeks.

\subsection{Assessment}

This was a non compulsory activity. Each participation on the forum added 0,05 extra points in the final subject mark up to maximum one extra point as long as the comments fulfilled the rules. The grading system in Spain ranges beteween 0 to 10 , where 10 is the best mark and 0 the worse, and the pass is achieved with 5 . Nevertheles, to taken into account the score of the forum activity, the students had to get a minimum of 4 in the written exam of the subject.

\section{Results}

The implementation of this forum-activity within the subject "World Economy" produced good results. Regarding participation, 51 out 76 pupils $(67,1 \%)$ participated in the forum. A total of 877 comments were posted on the forum, 176 of these were written by professor. None of them had to be removed due to disrespectful or insulting content. It was detected 35 copied writings from other websites which were not considered in the assessment. Regarding the new topics opened by students, some of them were quite suitables but other were more distant to the syllabus although these were not eliminate. Table 2 , shows some of the most relevant topics proposed in the forum by students.

Severel students posted about the economic questions regarding the Catalonian crisis. This is a very sensitive political issue exceeding the subject content and might result in a nasty discussion among pupils due the tense atmosphere involving this problem. Therefore, the topic related with this were blocked.

A topic about electric cars was the most dicussed with 42 comments. In general terms, the participants showed interest in the activity and their participations were quite accurate. Neverthless, some ideas were repeated, specially in the last days in which the forum stayed opened.

To assess the level of satisfaction of the students, an online survey was available during the last two weeks. It consisted of a enquiry in which pupils could give their opinion and propose improvings about the activity. As filling this survey was no mandatory, anonysmised and not providing additional mark, only two studenst replied it, but their responses were very positive. 
Table 2: Topics proposed by students

\section{TOPICS}

The image of the Spanish economy abroad

The Banco Popular purchase by Banco Santander

Advantages and disadvantages of international commerce

The digital challenge in small business

Solutions to save the oceans

Sustainable growth

Outsourcing

Economic repercussions of the Catalan crisis ( 5 topics)

The rise of the oil price and renewable energies

Offshoring in textile industry

The inflation in Spain

Household debt in Spain

Unemployment in Spain

Spanish self-employed workers law

Spnish tax amnesty

Relationship between happiness and wealth in Qatar

The role of stock market

Basic income

Draught in Spain

Alibaba investment in research centers

Space debris

The highest growing economies

Electric cars

Spanish trade deficit

The Syria’s war 


\section{Discussion}

We firmily thinks that specially in subjects within the social science field, it is basic to connect the subjects syllabus with reality. It is important to offer tools to understand past and current dynamics of society, and therefore to be capable to prepare for the future.

In the case of economics and business administration degrees, it is important to remark that reality it is much more complicate that the theoretical economic models. A good professional in the field, should keep in touch with real cases of the economy in order to understand as it is basic to introduce new social variables which are not reported in the theoretical models.

With this goal in mind, we proposed a forum-activity to promote among students critical thinking about real and contemporary economic topics.

By the implementation of this activity, we have verified it's utility in achiving the teaching goals. And that is, the forum-activity encouraged the active and autonomous participation of students and they also train they critical and respectful thinkin on current economic problems.

There are some points in this activity which may be enhanced. For instane, allowing students to create new topics encourage the participation and the motivation but It also provoke some drawbacks. For this reason, any student wanting to initiate new topic, send a electroni mail to professor for his validation and approval. In this way, new threads are more suitable and non-repeated.

This activity can be applied to other subjects in the Economics and Business administration degrees, specially in Macroeconomics, Marketing or Corporate Finance or even other university degrees.

The assessment may also vary depending on the characteristics and context of each subject. Mandatory participation, assessment criteria modification or greater demand in the content publication are some of the possible modification that could be introduced in the future.

\section{Acknowledgements}

Acknowledges to the project EstadísTIC@ i MatemàTIC@, Servei de Formació Permanent i Innovacio Educativa (SFPIE) de la Universitat de València. 


\section{References}

Thomas, M.J.W.: Learning within incoherent structures: the space of online discussion forums. J. Comput. Assist. Learn. 18, 351-366 (2002). doi:10.1046/j.02664909.2002.03800.x

Eileen, W., Jones, A., Barker, P., van Schaik, P.: Using e-learning dialogues in higher education. Innov. Educ. Teach. Int. 41, 93-103 (2004). doi:10.1080/147032903200017274

Lee, V.S., Greene, D.B., Odom, J., Schechter, E., Slatta, R.W.: What is Inquiry-Guided Learning? In: Lee, V.S. (ed.) Teaching and Learning through Inquiry: A Guidebook for Institutions and Instructors (2004)

Sakai: Poliformat, https://poliformat.upv.es/portal/site/!gateway-en/tool/9d61d2a6-51024570-bdac-c92c458eac77

Ferguson, C.: Inside Job. Sony Pictures Classics, United States (2010) 